\title{
On the correlation between Nd:YAG laser-induced wettability characteristics modification and osteoblast cell bioactivity on a titanium alloy
}

\author{
J. Lawrence ${ }^{1}$, L. Hao ${ }^{1}$ and H.R. Chew ${ }^{2}$ \\ ${ }^{1}$ Wolfson School of Mechanical and Manufacturing Engineering, Loughborough University, \\ Leicestershire, LE11 3TU, Great Britain. \\ ${ }^{2}$ Manufacturing Engineering Division, School of Mechanical \& Production Engineering, Nanyang \\ Technological University (NTU), 50 Nanyang Avenue, Singapore 639798.
}

\section{Correspondence}

Dr. Jonathan Lawrence

Manufacturing Engineering Division,

School of Mechanical \& Production Engineering,

Nanyang Technological University (NTU),

50 Nanyang Avenue,

Singapore 639798.

Tel : (+65) 67905542

Fax : (+65) 67911859

e-mail : mjlawrence@ntu.edu.sg 


\begin{abstract}
The factors responsible for modifications to the wettability characteristics of a titanium (Ti6Al4V) alloy bio-metal following Nd:YAG laser treatment and the effects thereof on the response of osteoblast cells were considered in this work. It was found that interaction of the Nd:YAG laser beam with the Ti6A14V alloy resulted in the wettability characteristics of the bio-metal improving. Such improvements in the wettability characteristics of the Ti6Al4V alloy were found to be due to: an increase in the surface roughness; and increase in the surface oxygen content and an increase in the polar component of the surface energy. From the cell response tests it was determined that the osteoblast cell adhesion and proliferation on the Nd:YAG laser treated Ti6Al4V alloy samples was considerably greater than on the untreated samples. By isolating the effects of surface roughness it was possible to confirm or refute the existence of a correlation between wettability characteristics and osteoblast cell bioactivity for the Nd:YAG laser treated Ti6Al4V alloy. The findings indicated that the aspects of wettability characteristics: surface oxygen content and polar component of the surface energy play an important role in promoting cell proliferation, particularly when surface roughness was simultaneously increased. Thus it was possible to conclude that the wettability characteristics of the Nd:YAG laser treated Ti6Al4V alloy were correlated to osteoblast cell bioactivity.
\end{abstract}




\section{Introduction}

To be suitable for the construction of surgical prostheses, a bio-metal should possess several properties ideal for bone and joint replacement. These are largely physical and mechanical features such as excellent fatigue and tensile strength, superior corrosion and wear resistance, low modulus of elasticity, good hardness and low density [1]. Titanium alloys are probably the most common materials used in surgical implants and devices, and in recent years has become the bio-metal of choice in dentistry.

The orthopaedic and dental implant industry is based entirely on favourable interaction at the bonetitanium interface - osseointegration. Moreover, it is clear that osseointegration is a property of titanium implant surfaces. The surface modification of titanium implants is an active area of research for two reasons. The first reason is to increase the rate of successful implantation from satisfactory, as it is today, to excellent. The second is to induce acceleration of normal bone healing phenomena as this would allow early of immediate loading of the implant, which would have significant implications in terms of decreased patient morbidity, patient physicology and health care costs.

When titanium alloys are implanted into a complicated and aggressive physiological in vivo environment, the oxide stability might be affected, resulting in an increase metal ion release [2-5]. In order to improve the biocompatibility of titanium alloys, various surface treatments are carried out. According to Puleo and Nanci [6], there are basically three different approaches to the surface modification of bone-contacting titanium implants: physicochemical methods; morphological methods and biochemical methods. Of the three, morphological methods are the most widely applied. This category includes techniques such as sandblasting and acid etching, and aims to direct interfacial interactions at the bone-titanium interface through the precise modification of surface topography. Biochemical methods of surface modification offer an alternative or supplement to physicochemical or morphological methods. Biochemical methods are intended to control the tissue-titanium interface through the immobilisation and/or delivery of proteins, enzymes or peptides for the purpose of inducing specific cell and tissue responses. Whichever approach is adopted, cellular behaviour, namely adhesion, morphologic change, functional alteration, proliferation and differentiation are greatly affected by surface properties, such as roughness, chemical composition, wettability and morphology of the oxide on the titanium. Indeed, most of the surface treatments are variants of surface machining, sand blasting or plasma spraying, all which have the potential to give rise to surface contamination.

Due to the rapid and specific modification of organic and inorganic materials, laser surface processing has aroused growing interests and been proven to be a controllable and flexible technique for modifying the surface properties of materials. It is recognised within the currently published work that laser irradiation 
of material surfaces can affect their wettability characteristics. Previously Heitz et al [7], Henari and Blau [8], and Olfert et al [9] have found that excimer laser treatment of metals results in improved coating adhesion attributed to the fact that the excimer laser treatment resulted in a smoother surface and as such enhanced the action of wetting. It was demonstrated that five pulses per area of $\mathrm{CO}_{2}$ laser treatment was sufficient to produce a fully wettable mild steel surface. The wettability was influenced by the surface exposing time (SET) after laser treatment [10]. Self-fluxing Fe-Cr-Ni-B-Si alloy powders with various Ni contents were laser clad on medium carbon steel substrates [11]. Lawrence and Li [12, 13] revealed that the interaction of $\mathrm{CO}_{2}, \mathrm{Nd}$ Y YAG, HPDL, and excimer laser radiation with the surface of selected metals gave rise to changes in the wettability characteristics of the material. It was observed that interaction of the mild steel with Nd:YAG and HPDL radiation brought about an improvement in the wettability characteristics of the steel. Yet, despite a growing amount of work conducted with metal, no work has been conducted so far on the feasibility of the laser surface treatment process for the modification of the wettability characteristics of bio-grade metals.

In the light of recent research by Hao et al [14], which demonstrated the feasibility of using a $\mathrm{CO}_{2}$ laser to alter the wettability characteristics and in turn, the biocompatibility, of a MgO-PSZ bioceramic, this work aims to explain and analyse the factors responsible for modifications to the wettability characteristics of a titanium alloy bio-metal following Nd:YAG laser treatment and to correlate these changes in terms of the cell response of human osteoblast cells.

\section{Experimental procedures}

\subsection{Materials}

In this study a Ti6A14V ELI alloy (F136) was used. The as-received Ti6A14V alloy (ground annealed) was in the form of round bar with a diameter of $28.5 \mathrm{~mm}$ (Carpenter, Inc.). For experimental purposes, the round bar was divided into 16 sections each of $3 \mathrm{~mm}$ thickness with a cutting machine (Miniton; Struers, $\mathrm{GmbH}$ ) using a diamond rimmed cutting blade and used as received prior to Nd:YAG laser treatment. The 15 divided sections were then separated into two groups of eight samples, with the groups being: untreated and $\mathrm{Nd}: \mathrm{YAG}$ laser treated.

\subsection{Laser processing}

A $400 \mathrm{~W}$ Nd:YAG laser (MAHO, Ltd.) was used in this work. The Nd:YAG laser emitted a TEM To beam at $1.064 \mu \mathrm{m}$ and was operated in the pulsed mode. The defocused Nd:YAG laser beam was fired back and forth across the surfaces of the bio-metals by traversing the samples beneath the laser beam using the $\mathrm{x}$ and $y$-axis of the computerised numerical control (CNC) gantry table. The laser energy density (fluence) 
of the laser beam incident on the surface of the Ti6Al4V alloy was set by fixing the power at $200 \mathrm{~W}$ and using a beam spot size of $3.5 \mathrm{~mm}$ in diameter, while the traverse speed was fixed at $20 \mathrm{~mm} / \mathrm{min}$.

\subsection{Morphological, chemical and phase analysis}

The surface roughness of the samples was measured by a surface profilometer (Surface Tester SV-600; Mitutoyo, Inc.). The surface and cross-section characteristics of the untreated and Nd:YAG laser treated Ti6Al4V samples were examined without etching using optical microscopy and scanning electron microscopy (SEM) (JSM 5600LV; JEOL, Ltd.). In order to determine any changes that may have occurred in the chemical make-up of the Ti6Al4V alloy following Nd:YAG laser treatment, the samples were examined using energy dispersive X-ray analysis (EDX) to obtain the chemical constituents and Xray photoemission spectroscopy (XPS) to ascertain the elemental content. XPS (AXIS Ultra; Kratos, Inc.) analysis was performed. Any changes in the phase of the Ti6Al4V alloy were detected by means of X-ray diffraction (XRD) (PW 1830; Philips, Ltd.).

\subsection{Wettability characteristics analysis}

To investigate the effects of Nd:YAG laser radiation on the wetting and surface energy characteristics of the Ti6Al4V alloy, wetting experiments were conducted. The experiments were comprised of control experiments carried out using the sessile drop technique with a variety of control test liquids (human blood, human blood plasma, glycerol and 4-octanol) with known surface energy properties [27]. Thus it was possible to quantify any surface energy changes in the Ti6Al4V alloy resulting from Nd:YAG laser interaction. The experiments were conducted in normal atmospheric conditions at a temperature of $20^{\circ} \mathrm{C}$. The droplets were released in a controlled manner onto the surface of the Ti6Al4V alloy samples (untreated and Nd:YAG laser treated) from the tip of a micropipette, with the resultant volume of the drops being approximately $16.5 \mu$ l. Each experiment lasted for three minutes with profile photographs of the sessile drops being obtained every minute. The contact angles, $\theta$, were then measured with a mean value being subsequently determined. The standard deviation due to experimental error was calculated as being $\pm 0.34^{0}$.

\subsection{Biological analysis}

The human osteoblastic cell line hFOB 1.19 was obtained from the American Type Culture Collection (Manassas, Inc.). These cells were cultured in a medium containing a 1:1 mixture Dulbecco's Modified Eagle's medium without phenol red and Ham's F12 medium with $2.5 \mathrm{mM}$ L-glutamine (D-MEM/F-12 Medium), supplemented with 10\% foetal bovine serum (ATCC) and $0.3 \mathrm{mg} / \mathrm{ml} \mathrm{G} 418$ (Calbiochem, Inc.) in a $37^{\circ} \mathrm{C}$, humidified, $5 \% \mathrm{CO}_{2} / 95 \%$ air incubator. 
Cytotoxicity tests consisted of the quantification of the activity of lactate dehydrogenase (LDH) in culture medium of cells in contact with the samples. The activity of the LDH enzyme rises when cells are damaged: the LDH activity induced by the untreated and selected Nd:YAG laser treated specimens in triplicate were compared to that induced by a toxic agent (Triton X100 0.05\% in PBS) and to that induced by a culture polystyrene plate (NUNC, Inc.). The cell culture plate was used as a negative control and a Triton toxic agent as a positive control.

For cell adhesion analysis, osteoblasts were enzymatically lifted from polystyrene tissue culture flasks until cell confluence using $1 \mathrm{ml}$ Trypsin-EDTA (0.25\% Trypsin/0.53 mM EDTA Solution) before suspension in the culture medium. The Ti6A14V alloy samples were placed in a 24-well tissue culture polystyrene plate (Falcon, BP) under a sterile environment and sterilized in $70 \%$ ethanol for $24 \mathrm{~h}$. The samples were rinsed by PBS and then were seeded with cell suspension. To analyse the cell attachment and morphology, the untreated and laser treated specimens were seeded with $0.5 \mathrm{ml}$ cell suspension of $1 \mathrm{x}$ $105 \mathrm{cell} / \mathrm{mL}$ for $24 \mathrm{~h}$ cell culture, then dehydrated in a graded ethanol series, critical point dried with $\mathrm{CO}_{2}$ and gold coated for SEM analysis.

Cell proliferation on each specimen was measured by MTT assay. The osteoblast cells culture 7 days on each specimen were gently washed with phosphate-buffered saline and were measured by MTT assay using 3 (4,5-dimethyl-thiazole-2-yl) 2, 5-diphenyl tetrazolium bromide (MTT; Sigma, Inc.). The MTT solution was added to each specimen and the cells were incubated for $4 \mathrm{~h}$ at $37^{\circ} \mathrm{C}$, then medium was replaced with dimethylsulfoxide. Absorbance of the solution was measured with an instrument plate reader (EL312; Bio-Tek, Inc.) at $490 \mathrm{~nm}$.

\subsection{Statistics}

Statistical analysis was performed with a SPSS v.12 software package (SPSS/PC, Inc.). Data are reported as mean $\pm \mathrm{SD}$ at a significance level of $p<0.05$. After having verified normal distribution and homogeneity of variances, one-way ANOVA and Scheffé's post hoc multiple comparison tests were done.

\section{Wettability characteristics modification following Nd:YAG laser treatment}

Nd:YAG laser treatment of the Ti6Al4V alloy resulted in changes to the wettability characteristics of the material. These modifications to the wettability characteristics manifested themselves in the form of variations in the measured $\theta$ with selected control test liquids. Indeed, it was observed that for all the control test liquids Nd:YAG laser treatment effected a reduction in the measured $\theta$. This reduction in $\theta$ 
was brought about by changes in the surface properties of the Ti6Al4V alloy, namely changes to the surface roughness, the microstructure, phase, chemical composition and the surface energy.

\subsection{Surface roughness analysis}

It was observed that for the Ti6Al4V alloy, Nd:YAG laser treatment actually caused the surface to be rougher, increasing from 0.21 to $0.45 \mu \mathrm{m}$. The observed increase in the wettability characteristics of the Ti6Al4V alloy following Nd:YAG laser treatment is in agreement with the findings of Neumann [15]. In this work, Neumann et al. developed a model similar to that for heterogeneous solid surfaces to account for surface irregularities, being given by a rearrangement of Wenzel's equation:

$$
\gamma_{s l}=\gamma_{s v}-\left(\frac{\gamma_{l v} \cos \theta_{w}}{r}\right)
$$

where, $\gamma_{s l}$ is the surface energy at the solid-liquid interface, $\gamma_{s v}$ is the surface energy at the solid-vapour interface, $\gamma_{l v}$ is the surface energy at the liquid-vapour interface, $r$ is the roughness factor defined as the ratio of the real and apparent surface areas and $\theta_{w}$ is the contact angle for the wetting of a rough surface. Eq. (1) shows clearly that if the roughness factor, $r$, is large, that is the solid surface is rough, then $\gamma_{\mathrm{sl}}$ will become small. So according to the rearranged Young's equation:

$$
\cos \theta=\frac{\gamma_{s v}-\gamma_{s l}}{\gamma_{l v}}
$$

a reduction in $\theta$ will be realised by the liquid if $\theta<90^{\circ}$. Still, the increase in wettability characteristics (decrease in $\theta$ ) of the Ti6A14V alloy following Nd:YAG laser treatment appears to be disproportionate to the increase in surface roughness. Such an occurrence is quite possible because laser treatment inherently alters other factors besides surface roughness simultaneously, namely the surface chemistry (by way of surface oxygen content) and the surface energy characteristics (by way of the microstructure). In this instance, the fact that the wettability characteristics of the Ti6Al4V alloy increased after Nd:YAG laser treatment indicates that these other factors played a part in governing the wettability characteristics of the bio-metal.

\subsection{Microstructure, phase and chemical composition analysis}

SEM images of the Ti6Al4V alloy samples (see Fig. 1) showed that as the samples undergo Nd:YAG laser surface treatment, melting and resolidification of the surface occurs. In this instance, it is clear from Fig. 1 that the melting and solidification regime experienced by the Ti6Al4V alloy occasioned the 
observed increase in surface roughness. This observed increase in the surface roughness following resolidification indicates that the liquid Ti6A14V alloy flow within the meltpool was turbulent.

The results of an EDX analysis of the surface of the Ti6Al4V alloy indicated that Nd:YAG laser treatment did not alter that chemical composition of the surface of the Ti6Al4V alloy since Ti, $\mathrm{Al}$ and $\mathrm{V}$ the basic elements of the Ti6Al4V alloy - were still present in similar proportions on the surface of the alloy before and after Nd:YAG laser treatment. Having said that, the XRD analysis (see Fig. 2) did reveal that an oxide diffraction peak at $38.5^{\circ}$ was generated after Nd:YAG laser treatment. This finding is evidence that the surface of Ti6Al4V alloy was oxidised following the Nd:YAG laser process, with the oxide layer consisting of rutile. This is significant as many transient oxides may be formed on a $\mathrm{Ti}$ or $\mathrm{Ti}$ alloy surface, but only rutile or anatase are known to have a positive effect on biocompatibility. This oxidation of the Ti6Al4V alloy samples came about because the surface was superficially melted by the Nd:YAG laser beam during treatments. This in turn led to oxygen diffusion through the molten material and subsequently to the oxidation of the Ti6Al4V alloy surface.

An XPS analysis of the untreated and Nd:YAG laser treated Ti6A14V alloy samples showed that the surface oxygen content of the samples increased after Nd:YAG laser treatment, increasing from 25.04 to $53.84 \mathrm{wt} \%$. It is postulated that this oxidation of the Ti6Al4V alloy surface following Nd:YAG laser treatment was occasioned by the melting and resolidification regime experienced by the bio-metal. Since the hydrophilic nature of the surface improves with increased oxygen content [16], then it would be valid to presume that the increase in oxygen content of the surface of the Ti6Al4V alloy following Nd:YAG laser treatment was an influential factor in occasioning the improved wetting performance of the material.

\subsection{Surface energy analysis}

The intermolecular attraction that is responsible for surface energy results from a variety of intermolecular forces whose contribution to the total surface energy is additive [17]. The majority of these forces are functions of the particular chemical nature of a certain material, and as such the total surface energy, $\gamma$, comprises of $\gamma^{p}$ (polar or non-dispersive interaction) and $\gamma^{d}$ (dispersive component; since van der Waals forces are present in all systems regardless of their chemical nature). Therefore, the surface energy of any system can be described by [17]

$$
\gamma=\gamma^{d}+\gamma^{p}
$$

Similarly, the total work of adhesion, $W_{a d}$, can be expressed as the sum of the different intermolecular forces that act at the interface [17]: 


$$
W_{a d}=W_{a d}^{d}+W_{a d}^{p}=2\left(\gamma_{s v}^{d} \gamma_{l v}^{d}\right)^{1 / 2}+2\left(\gamma_{s v}^{p} \gamma_{l v}^{p}\right)^{1 / 2}
$$

where $W_{a d}^{d}$ is the dispersive component of the work of adhesion, $W_{a d}^{p}$ is the polar component of the work of adhesion, $\gamma_{s v}^{d}$ is the dispersive component of the surface energy at the solid-vapour interface, $\gamma_{l v}^{d}$ is the dispersive component of the surface energy at the liquid-vapour interface, $\gamma_{s v}^{p}$ is the polar component of the surface energy at the solid-vapour interface and $\gamma_{l v}^{p}$ is the polar component of the surface energy at the liquid-vapour interface. $\theta$ for solid-liquid systems can be related to the surface energies of the respective liquid and solid by

$$
\cos \theta=\frac{2\left(\gamma_{s v}^{d} \gamma_{l v}^{d}\right)^{1 / 2}+2\left(\gamma_{s v}^{p} \gamma_{l v}^{p}\right)^{1 / 2}}{\gamma_{l v}}-1
$$

In accordance with studies conducted by Fowkes [17] and Agathopoulos et al. [18], it is possible to estimate reasonably accurately the value of $\gamma_{s v}^{d}$ for the untreated and Nd:YAG laser treated Ti6Al4V alloy by plotting the graph of $\cos \theta$ against $\left(\gamma_{l v}^{d}\right)^{1 / 2} / \gamma_{\mathrm{lv}}$ in accordance with Eq. (5), with the value of $\gamma_{s v}^{d}$ being estimated by the gradient $\left(=2\left(\gamma_{s v}^{d}\right)^{1 / 2}\right)$ of the line which connects the origin $(\cos \theta=-1)$ with the intercept point of the straight line $\left(\cos \theta\right.$ against $\left.\left(\gamma_{l v}^{d}\right)^{1 / 2} / \gamma_{1 v}\right)$ correlating the data point with the abscissa at $\cos \theta=1$. Fig. 3 shows the best-fit plot of $\cos \theta$ against $\left(\gamma_{l v}^{d}\right)^{1 / 2} / \gamma_{\mathrm{lv}}$ for the untreated Nd:YAG laser treated Ti6A14V alloy-experimental control liquids system from which the values of $\gamma_{s v}^{d}$ given in Table 2 were deduced.

It can be seen clearly that the best-fit straight line for both the Nd:YAG laser treated Ti6Al4V alloy-liquid systems intercept the ordinate higher above the origin than those of the untreated sample. This is of great importance since interception of the ordinate close to the origin is characteristic of the dominance of dispersion forces acting at the Ti6Al4V alloy -liquid interfaces of the untreated samples, resulting in poor adhesion $[17,19]$. On the other hand, an interception of the ordinate well above the origin is indicative of the action of polar forces across the interface, in addition to dispersion forces, hence improved wettability and adhesion is promoted $[17,19]$. Furthermore, because none of the best-fit straight lines intercept below the origin, then it can be said that the development of an equilibrium film pressure of adsorbed vapour on the Ti6A14V alloy (untreated and Nd:YAG laser treated) did not occur [17, 19].

Again, in accordance with studies conducted by Fowkes [17] and Agathopoulos et al. [18], it is not possible to determine $\gamma_{s v}^{p}$ for the untreated and Nd:YAG laser treated Ti6Al4V alloy directly from Fig. 3. 
This is because the intercept of the straight line $\left(\cos \theta\right.$ against $\left.\left(\gamma_{l v}^{d}\right)^{1 / 2} / \gamma_{\mathrm{lv}}\right)$ is at $2\left(\gamma_{s v}^{p} \gamma_{l v}^{p}\right)^{1 / 2} / \gamma_{\mathrm{lv}}$, and thus only refers to individual control liquids and not the control liquid system as a whole; however, it has been established that the entire amount of the surface energies due to dispersion forces either of the solids or the liquids are active in the wettability performance $[17,20]$. As such, it is possible to calculate $\gamma_{s v}^{p}$ using

$$
\left(\gamma_{s v}^{p}\right)^{1 / 2}=\frac{\left(\gamma_{s v}^{d}\right)^{1 / 2}(a-1)}{1.3}
$$

From the best-fit straight line plots of $W_{a d}$ against $W_{a d}^{d}$ for the Ti6Al4V alloy when it is both untreated and Nd:YAG laser treated, it was possible to determine the value of the constant, $a$, for each separate condition of the Ti6A14V alloy. Since $\gamma_{s v}^{d}$ has already been determined for the untreated and Nd:YAG laser treated Ti6A14V alloy from Fig. 3, then it is possible to calculate $\gamma_{s v}^{p}$ for untreated and Nd:YAG laser treated Ti6Al4V alloy using Eq. (6) (see Table 2).

As one can see from Table 2, Nd:YAG laser treatment of the surface of the Ti6Al4V alloy brought about a small increases in $\gamma_{s v}^{p}$. It is believed that the change in $\gamma_{s v}^{p}$ is the result of the melting and resolidification of the Ti6Al4V alloy surface, which gave rise to a different, more polar microstructure. Such an increase in $\gamma_{s v}^{p}$ of the Ti6Al4V alloy will certainly have a positive effect upon the action of wetting and adhesion.

\section{Biological analysis}

\subsection{Cell cytotoxicity}

The LDH activity in culture media obtained from cells cultured on all the tested materials was found to be not significantly different from the negative control as shown in Fig. 4, indicating that untreated and $\mathrm{CO}_{2}$ laser treated Ti6A14V alloy were not cytotoxic.

\subsection{Cell adhesion and morphology}

Generally, cells in contact with a material's surface will firstly attach, then adhere and finally spread. From Fig. 5 it is quite clear that the adhesion and spreading of osteoblast cells was influenced by the Nd:YAG laser treatment. Whereas the cells on the untreated surface presents the initial stage of the adhesion with individual cells covering small surface area and not spreading, the cells on the Nd:YAG laser treated sample exhibit a good state of adhesion and flattening to cover more surface area. This 
signifies that the cells achieved a better adhesion on the Nd:YAG laser treated sample than on the untreated sample. This suggests that the surface properties generated by the Nd:YAG laser treatment were more favourable for osteoblast cell adhesion.

\subsection{Cell proliferation}

The MTT results given in Fig. 6 show the cell proliferation on the surface of the untreated and Nd:YAG laser treated Ti6Al4V alloy specimens for 7 days. It can be seen that the Nd:YAG laser treated samples allowed a significantly higher degree of cell proliferation as compared to the untreated sample. The statistical analysis reveals that cell proliferation significantly improved on the Nd:YAG laser treated sample as compared with that on the untreated sample. These results reveal that the surface generated on the Ti6Al4V alloy by the Nd:YAG laser treatment is more favourable for cell proliferation than the untreated Ti6Al4V alloy surface.

\section{Relationship between wettability characteristics and cell response}

From the foregoing results it is clear the Nd:YAG laser treatment of the Ti6Al4V alloy enhanced the wettability characteristics of the material and that following Nd:YAG laser treatment, the Ti6Al4V alloy presented improved bioactivity in terms of osteoblast cell adhesion and proliferation. It is not possible, however, to conclude from these findings that the increased osteoblast cell bioactivity of the Ti6A14V alloy is correlated to the improvement of the wettability characteristics of the material. The reason that it is not possible to claim the existence of a correlation between wettability and osteoblast cell bioactivity for the Nd:YAG laser treated Ti6Al4V alloy is that the Nd:YAG laser treatment resulted in the surface roughness of the Ti6Al4V alloy increasing. Since surface roughness is known to influence osteoblast cell adhesion and proliferation, it is possible that the surface roughness increase alone could be responsible for the increased osteoblast cell bioactivity. So, for any correlation between wettability characteristics and osteoblast cell bioactivity for the Nd:YAG laser treated Ti6Al4V alloy to be confirmed or refuted, attention needs to be paid to the effects of increasing only the surface roughness of the Ti6Al4V alloy. This was done by taking an untreated Ti6A14V alloy sample and mechanically roughening the surface.

A mechanically roughened surface was obtained by evenly abrading the entire surface of the sample with polishing paper (180 grit $\mathrm{SiC}$ ). This was achieved by applying the polishing paper to the surface of the sample with moderate pressure and drawing it across the surface in different directions eight-times. Thereafter the morphological, chemical and phase properties were examined as in Section 2.3. Following this the wettability characteristics of the mechanically roughened samples were quantified in accordance with Section 2.4 and osteoblast cell bioactivity was assessed as in Section 2.5. 
A comparison of the MTT values for the untreated and mechanically roughened Ti6Al4V alloy samples given in Table 3 confirms that surface roughness does indeed affect osteoblast cell adhesion. As one can see from Table 3, the MTT value on the Ti6Al4V alloy increased markedly from 0.070 to 0.081 when the surface roughness was increased from $0.21 \mu \mathrm{m}$ in the untreated condition to $0.52 \mu \mathrm{m}$ by mechanical roughening. In addition, $\theta$ was observed to decrease from 41.84 to $36.39^{\circ}$, which is perhaps not surprising as surface roughness is known to be a factor influential in determining $\theta$, as demonstrated by Eqs (1) and (2). Significantly, Table 3 shows that the surface oxygen content and the $\gamma_{s v}^{p}$ of the sample subjected to mechanical roughening remained virtually the same as the untreated sample, thus indicating that the decrease in $\theta$ and the increase in surface roughness alone caused the MTT value to increase. The MTT value for the Nd:YAG laser treated sample was considerably larger that of the mechanically roughened sample, 0.113 compared to 0.081 , despite the slightly larger value of surface roughness on the mechanically roughened sample. Yet the surface oxygen content and the $\gamma_{s v}^{p}$ of the Nd:YAG laser treated sample were much higher. The value of $\theta$ was also found to be smaller by $5.45^{\circ}$. Since surface oxygen content and $\gamma_{s v}^{p}$, along with surface roughness, have been shown to play a role in governing the wettability characteristics of a Ti6Al4V alloy following $\mathrm{CO}_{2}$ laser surface treatment [21], it is to be expected that the Nd:YAG laser treated sample displays the lowest value of $\theta$.

Owing to the extensive body of literature attesting to the efficacy of surface roughness in enhancing biocompatibility, it is clear that the increase in surface roughness of the Ti6Al4V alloy following $\mathrm{Nd}$ :YAG laser treatment was responsible in part for the observed improvement in osteoblast cell bioactivity. Nevertheless, the wetting of a solid surface can be a predictive index of the biocompatibility of materials involved, so improvements in the wettability characteristics of the Ti6Al4V alloy would most possibly result in better biocompatibility. Indeed, a reduction in $\theta$ contributes to the enhancement in $W_{a d}$ of SBF and SBF+BSA on the Ti6Al4V alloy following Nd:YAG laser treatment. As both SBF and SBF+BSA have close chemical compositions to human body fluids, the improvements to the $W_{a d}$ of the Ti6A14V alloy surface towards these fluids would mean better suitability of the Ti6A14V alloy as a biomaterial after Nd:YAG laser treatment. Also, Hallab et al [22] demonstrated that surface free energy was a more important surface characteristic than surface roughness for cellular adhesion strength and proliferation. Schakenraad et al [23] found that, despite the great number of parameters interfering with cellular adhesion and spreading, the solid surface energy apparently is a dominated factor in cellular attachment to a polymer surface and remains so, even if the solid surface has been covered by a protein layer. Moreover, as discussed in the previously, the improvement of the wettability characteristics resulted in decrease of albumin adsorption and increase of fibronectin. The phenomena would be beneficial to cell adhesion since albumin is a non-adhesive protein and fibronectin is an adhesion protein. 
A previous study by Hao and Lawrence [24] also shows that the enhancement of the wettability characteristics of MgO-PSZ after $\mathrm{CO}_{2}$ laser treatment resulted in the better response of the human fibroblast cell and human osteoblast cell. The surface oxygen content of the Ti6Al4V alloy following Nd:YAG laser irradiation is much higher than the untreated sample. The improved performance of cell adhesion and proliferation is highly likely to be due to the augmentation of the surface oxygen content. It has been found that the biocompatibility of titanium implants is associated with the oxide on its surface [24]. The surface oxide layer on titanium is biocompatible and capable of interacting with surrounding biological fluids and cells when implanted in situ $[25,26]$. This layer, composed primarily of $\mathrm{TiO}_{2}$, is found superficially on both cp Ti and Ti6Al4V alloys [25, 27]. Thus, it is reasonable to postulate that the aspects of wettability characteristics: surface oxygen content and $\gamma_{s v}^{p}$, play an important role in promoting cell proliferation, particularly when surface roughness is simultaneously increased.

\section{Conclusions}

In this work a Nd:YAG laser was used to alter the surface properties of a titanium alloy (Ti6Al4V) with a view to rendering the material more wettable and with enhanced bioactivity towards osteoblast cells. The specific forms of cell response analysed were the cell adhesion and cell proliferation. In this way it was possible to determine the change in the degree of bioactivity of the Ti6A14V alloy after Nd:YAG laser treatment and relate this change to wettability characteristics modifications.

The findings of this study revealed that Nd:YAG laser surface treatment could alter the surface properties of a titanium alloy (Ti6Al4V) and thereby improve the wettability characteristics. Such improvements in the wettability characteristics of the Ti6Al4V alloy were found to be due to: (i) an increase in the surface roughness; (ii) and increase in the surface oxygen content and (iii) an increase in the polar component of the surface energy. From the cell response tests it was determined that the osteoblast cell adhesion and proliferation on the Nd:YAG laser treated Ti6Al4V alloy samples was considerably greater than on the untreated samples.

By introducing a mechanically roughened sample into the study, it was possible to isolate the effects of surface roughness and thus confirm or refute the existence of a correlation between wettability characteristics and osteoblast cell bioactivity for the Nd:YAG laser treated Ti6A14V alloy. The findings indicated that the aspects of wettability characteristics: surface oxygen content and polar component of the surface energy played an important role in promoting cell proliferation, particularly when surface roughness was simultaneously increased. Consequently, it was possible to conclude that the wettability characteristics of the Nd:YAG laser treated Ti6A14V alloy were correlated to osteoblast cell bioactivity. 
Also, it is evident from this work that Nd:YAG laser treatment could be a more effective way to improve osteoblast cell adhesion than the traditional methods currently available, especially mechanical roughening.

\section{References}

1. K. Bordji, J.Y. Jouzeau, D. Mainard, E. Payan, P. Netter, K.T. Rie, T. Stucky and M. Hage-Ali, Biomaterials, 17 (1996) 929.

2. J. Lincks, B.D. Boyan, C.R. Blanchard, C.H. Lohmann, Y. Liu, D.L. Cochran, D.D. Dean and Z. Schwartz, Biomaterials, 19 (1998) 2219.

3. K. Anselme, P. Linez, M. Bigerelle, D. Le Maguer, A. Le Maguer, P. Hardouin, H.F. Hildebrand, A. Iost and J.M. Leroy, Biomaterials, 21 (2000) 1567.

4. D.D. Deligianni, N. Katsala, S. Ladas, D. Sotiropoulou, J. Amedee and Y.F. Missirlis, Biomaterials, $22(2001) 1241$.

5. L. Ponsonnet, V. Comte, A. Othmane, C. Lagneau, M. Charbonnier, M. Lissac and N. Jaffrezic, Mater. Sci. Eng. C, 21 (2002) 157.

6. D.A. Puleo and A. Nanci, Biomaterials, 20 (1999) 2311.

7. J. Heitz, E. Arenholz, T. Kefer, D. Bauerle, H. Hibst and A. Hagemeyer, Appl. Phys. A. A55 (1992) 391.

8. F. Henari and W. Blau, Appl. Optics, 34 (1995) 581.

9. M. Olfert, R. E. Mueller, W. Duley, T. North, J. Hood and D. Sakai, J. Laser Apps, 8 (1996) 79.

10. G.W. Critchlow, C. A. Cottam, D.M. Brewis and D.C. Emmony, Int. J. Adhesion Adhesives, 17 (1997) 143.

11. W. Song, P. Zhu and K. Cui, Surf. Coat. Tech. 80 (1996) 279.

12. J. Lawrence and L. Li, Appl. Surf. Sci. 154-155(2000) 664.

13. J. Lawrence and L. Li, J. Laser Apps. 14 (2002) 107.

14. L. Hao, J. Lawrence and K.S. Chian, J. Biomater. Apps. 19 (2002) 81.

15. W. Neumann, Adv. Colloid Interface Sci. 4 (1974) 438.

16. M. Ueki, M. Naka, I. Okamoto, J. Mater. Sci. Lett. 5 (1986) 1261.

17. F.M. Fowkes, Ind. Eng. Chem. 56 (1964) 40.

18. S. Agathopoulos, P. Nikolopoulos, J. Biomed. Mater. Res. 29 (1995) 421. 
19. D.K. Chattoraj and K. S. Birdi, Adsorption and the Gibbs Surface Excess, Plenum Press, New York, 1984.

20. R.J. Good and L.A. Girifalco, J. Phys. Chem. 64 (1960) 561.

21. L. Hao and J. Lawrence, Laser Surface Treatment of Bio-Implant Materials, Chichester, Great Britain: John Wiley \& Sons (2005).

22. N.J. Hallab, K.J. Bundy, K. O’Connor, R.L. Moses and J.J. Jacobs, Tissue Eng. 7 (2001) 55.

23. J.M. Schakenraad, H.J. Busscher, C.R.H. Wildevuur and J. Arends, J. Biomed. Mater. Res. 20 (1986) 773.

24. L. Hao and J. Lawrence, Mater. Sci. Eng. C, 23 (2003) 627.

25. B. Kasemo and J. Lausmaa, Surface science aspects on inorganic biomaterials, CRC Crit. Rev. Biocompat. 2 (1986) 335. ,

26. B.D. Ratner, D.G. Castner, T.A. Horbett, T.J. Lenk, K.B. Lewis and R.J. Rapoza, J. Vacuum Sci. Tech. A, 8 (1990) 2306.

27. I. Milosev, M. Metikos-Hukovic and H.H. Strehblow, Biomaterials, 21 (2000) 2103. 


\section{List of Figs.}

Fig. 1. SEM images of the (a) untreated and (b) Nd:YAG laser treated Ti6Al4V alloy.

Fig. 2. XRD plots of the (a) untreated and (b) Nd:YAG laser treated Ti6Al4V alloy.

Fig. 3. Plot of $\cos \theta$ against $\left(\gamma_{l v}^{d}\right)^{1 / 2} / \gamma_{\mathrm{lv}}$ for the untreated and Nd:YAG laser treated Ti6Al4V alloy in contact with the wetting control test liquids.

Fig. 4. The LDH activity on the positive and negative controls, untreated and Nd:YAG laser treated Ti6Al4V alloys. (There was significant statistical difference between the positive control and the untreated and Nd:YAG laser treated samples, and no statistical difference between the negative control and the untreated and Nd:YAG laser treated Ti6Al4V alloy samples. ${ }^{*}<<0.05$ )

Fig. 5. SEM image of osteoblast cells on Ti6A14V alloy when (a) untreated and (b) Nd:YAG laser treated. Fig. 6. MTT optical density of osteoblast cells grown on the untreated and Nd:YAG laser treated Ti6Al4V alloy after 7 days of cell culture. (There was significant statistical difference between the untreated sample and the Nd:YAG laser treated sample. ${ }^{*} \mathrm{p}<0.05$ ) 
Fig. 1

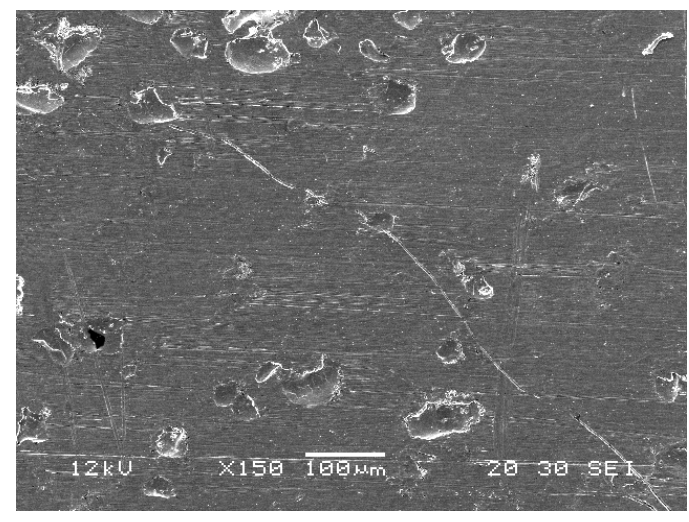

(a)



(b) 
Fig. 2.

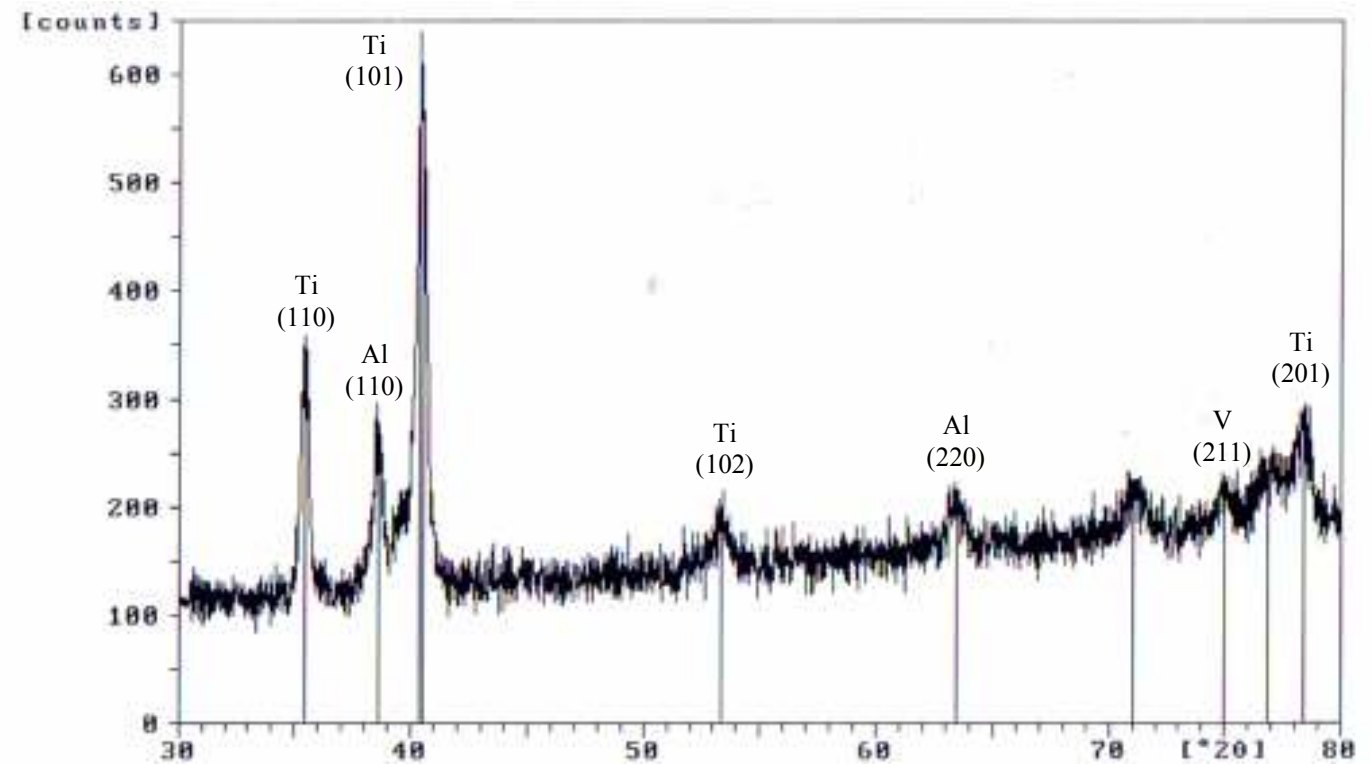

(a)

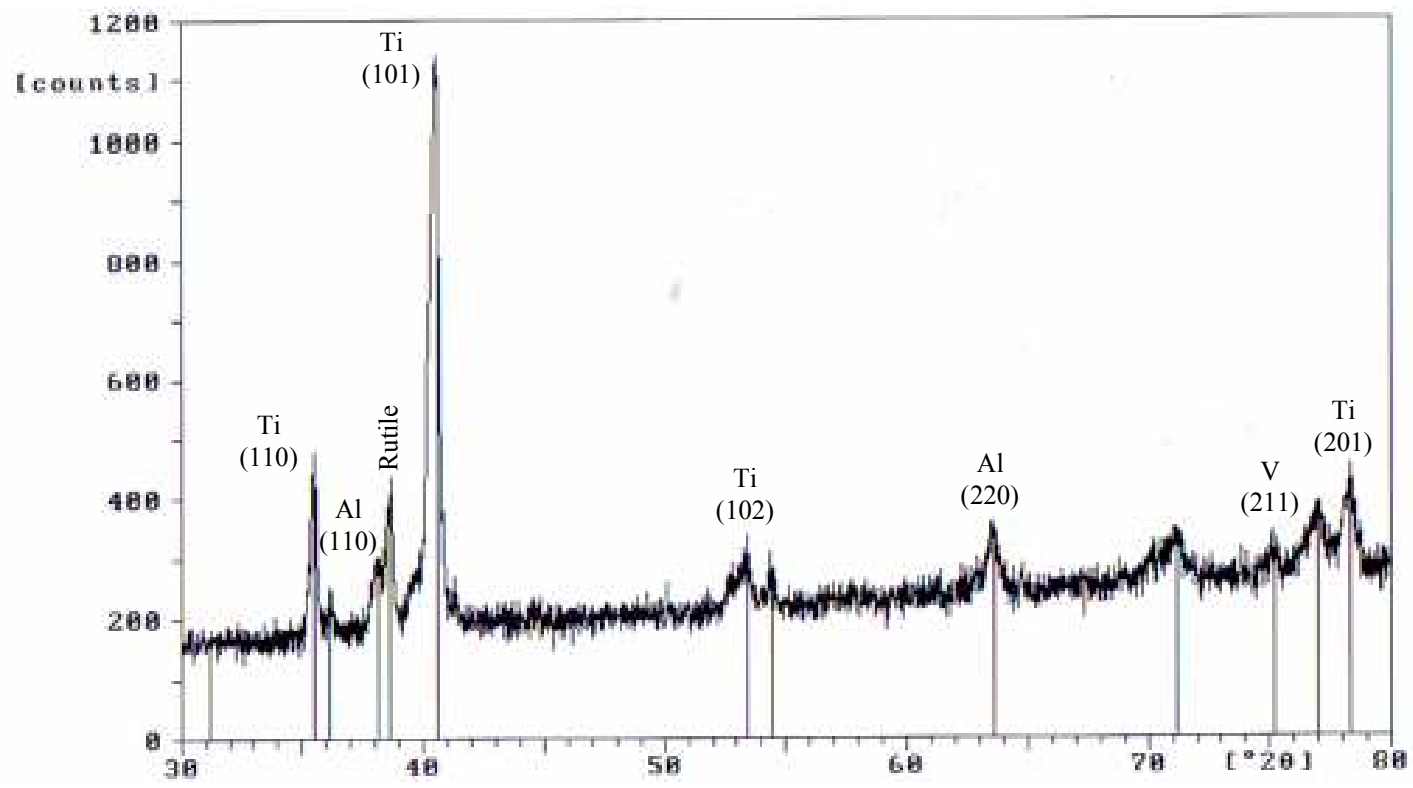

(b) 
Fig. 3




Fig. 4




Fig. 5

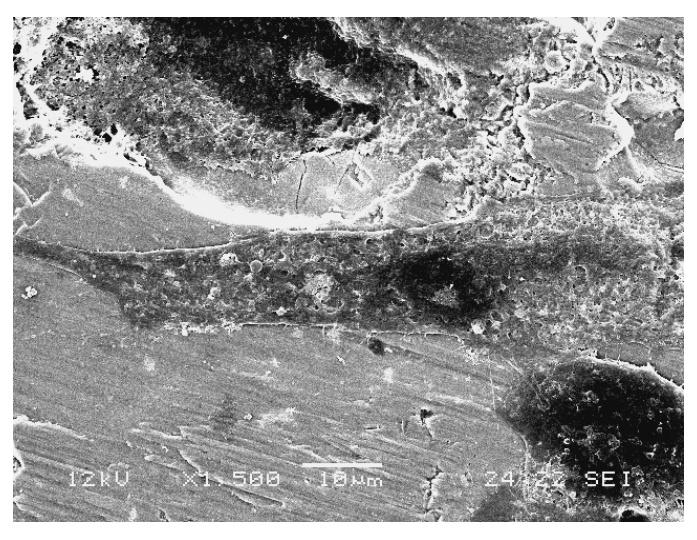

(a)

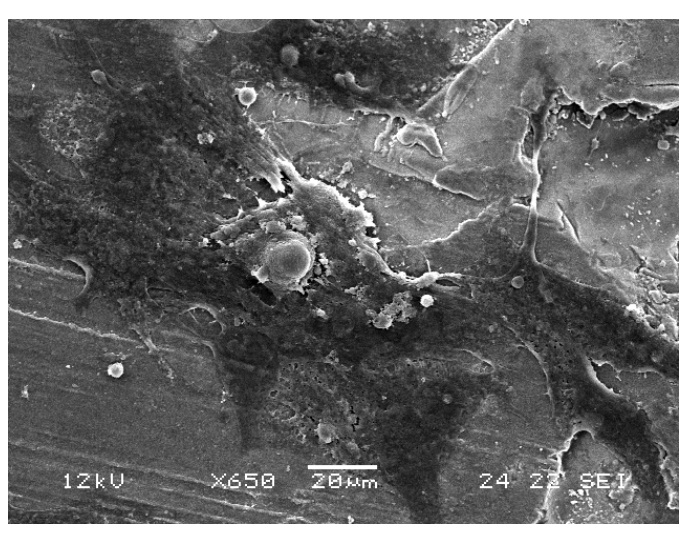

(b) 
Fig. 6

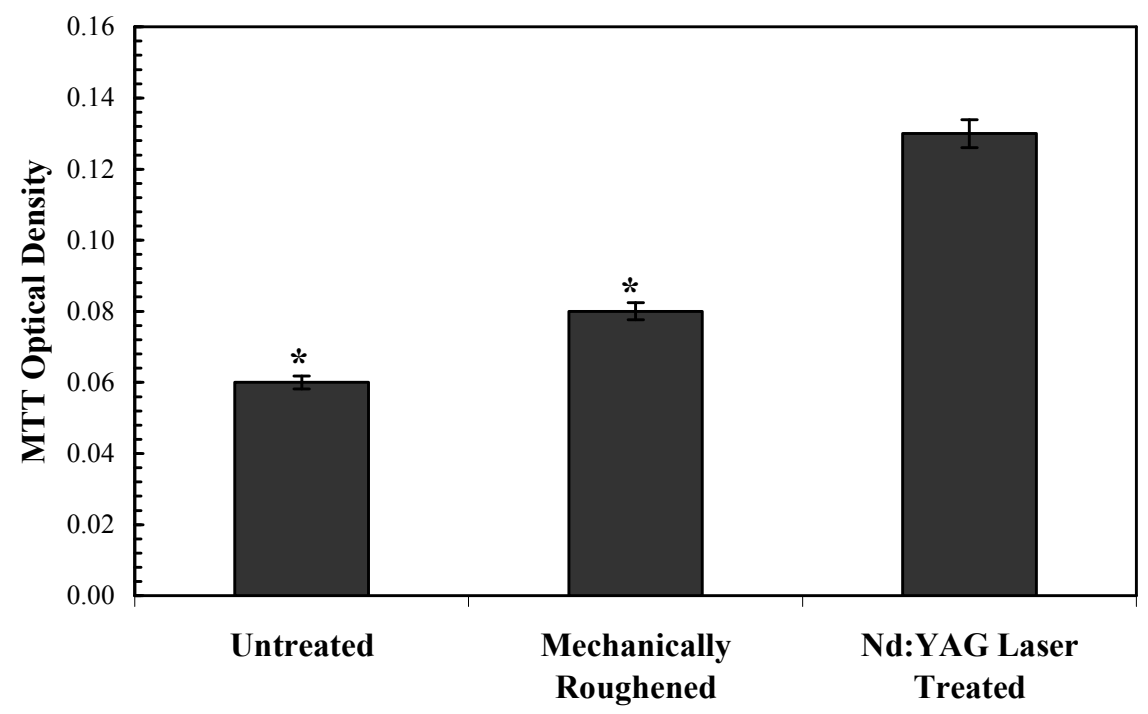




\section{List of Tables}

Table 1. Measured values of contact angle formed by the control test liquids with the untreated and Nd:YAG laser treated Ti6A14V alloy.

Table 2. Determined surface energy values for the untreated and Nd:YAG laser treated Ti6A14V alloy.

Table 3. Wettability characteristics and MTT optical density of osteoblast cells grown on the untreated, mechanically roughened and Nd:YAG laser treated Ti6Al4V alloy after 7 days of cell culture. 
Table 1

\begin{tabular}{lcc}
\hline Control Test Liquid & \multicolumn{2}{c}{ Contact Angle, $\boldsymbol{\theta}(\mathbf{d e g})$} \\
& Untreated & Nd:YAG laser Treated \\
\hline Human Blood & 60.10 & 35.66 \\
Human Blood Plasma & 52.41 & 28.96 \\
Glycerol & 41.84 & 28.35 \\
4-Octanol & 41.43 & 27.75 \\
\hline
\end{tabular}


Table 2

\begin{tabular}{lcc}
\hline Surface Energy Component & \multicolumn{2}{c}{ Material Condition } \\
\cline { 2 - 3 } & Untreated & Nd:YAG Laser Treated \\
\hline Dispersive component, $\left(\gamma_{s v}^{d}\right)$ & $73.08 \mathrm{~mJ} / \mathrm{m}^{2}$ & $75.27 \mathrm{~mJ} / \mathrm{m}^{2}$ \\
Polar component, $\left(\gamma_{s v}^{p}\right)$ & $5.45 \mathrm{~mJ} / \mathrm{m}^{2}$ & $9.85 \mathrm{~mJ} / \mathrm{m}^{2}$ \\
\hline
\end{tabular}


Table 3

\begin{tabular}{lccc}
\hline & \multicolumn{3}{c}{ Ti6Al4V Alloy Surface Condition } \\
\cline { 3 - 4 } & $\begin{array}{c}\text { As } \\
\text { Received }\end{array}$ & $\begin{array}{c}\text { Mechanically } \\
\text { Roughened }\end{array}$ & $\begin{array}{c}\text { Nd:YAG Laser } \\
\text { Treated }\end{array}$ \\
\hline Wettability Characteristics & & & \\
Contact angle, $\theta$ & $41.84^{0}$ & $36.39^{0}$ & $28.35^{0}$ \\
Surface roughness, Ra & $0.21 \mu \mathrm{m}$ & $0.52 \mu \mathrm{m}$ & $0.45 \mu \mathrm{m}$ \\
Polar surface energy, $\gamma_{s v}^{p}$ & $5.45 \mathrm{~mJ} / \mathrm{m}^{2}$ & $5.47 \mathrm{~mJ} / \mathrm{m}^{2}$ & $9.85 \mathrm{~mJ} / \mathrm{m}^{2}$ \\
Surface oxygen content & $25.04 \mathrm{wt} \%$ & $25.01 \mathrm{wt} \%$ & $53.84 \mathrm{wt} \%$ \\
\multicolumn{1}{c}{ Biological Aspect } & & & \\
MTT & 0.070 & 0.081 & 0.113 \\
\hline
\end{tabular}

